\title{
The Relationship between Oral Cancer and Oral Healthcare in Adults
}

\author{
Sung-Joong, Kim ${ }^{1}$, Young-Ran, Yeun ${ }^{2}$ and Hye-Young, Kim $^{3 *}$ \\ ${ }^{1}$ Dept. of Dental Hygiene, Kangwon National University, \\ ${ }^{2}$ Dept. of Physical Therapy, Kangwon National University, \\ ${ }^{3}$ Dept. of Nursing, Kwangwon National University \\ ${ }^{1}$ E-mail: lymphkim@kangwon.ac.kr, ${ }^{2}$ E-mail:yeunyr@kangwon.ac.kr, $*^{3} E$-mail: \\ khy0606@kangwon.ac.kr
}

\begin{abstract}
This study was conducted to address the need to prevent oral cancer and to lower its mortality rate based on the research on the knowledge about oral cancer and on the level of recognition of it. Moreover, the prevention of other diseases related to oral cavities is important for oral healthcare, and to prevent these diseases, the difference between the incidence of oral disease and that of oral cancer based on the degree of knowledge about oral health (i.e., the correlation between oral cancer and the degree of knowledge about oral health) was studied. A total of 298 adults residing in Kangwon Province who agreed to participate in this study were selected as study subjects. Each of them was provided a selfadministered survey questionnaire for data research, which he or she was to accomplish within two weeks from September 2014. For the results of the survey, the mean recognition of oral cancer was $19.98 \pm 6.59$ points, and the mean oral healthcare, $23.49 \pm 5.87$ points. The acknowledgement of oral cancer was statistically significantly higher at a younger age $(F=2.76, p=.042)$ and with a higher level of education $(F=2.62, p=.035)$. Oral healthcare was significantly higher in the female subjects $(t=-3.77, p=.000)$, in the group with a high level of education $(F=5.00, p=.001)$, in the non-smokers $(F=-4.23, p=.000)$, and in the group with regular exercise $(t=4.09, p=.000)$. The recognition of oral cancer and of the importance of good oral health and of preventing oral-cavity-related diseases showed a statistically significant static correlation. Based on the results of this study, the provision of education on oral cancer is deemed necessary as the recognition of oral cancer declined with a lower age, oral healthcare was well managed in the females, and oral health was good with a higher level of education. Also, the non-smokers had a high level of oral health, and oral health was well managed in the subjects who were exercising regularly.
\end{abstract}

Keywords: oral cancer, oral healthcare, oral cancer prevention

\section{Introduction}

In many countries, oral health is a relatively low priority, but the current rise in the cases of oral diseases has led to efforts to improve people's oral health and to integrate it into public health improvement initiatives [1].

Oral diseases such as dental caries, periodontal disease, and tooth loss play a key role in dental infection. The common diseases may be painful and debilitating, with a potential longterm impact on health and social outcomes [2]. In particular, cancer, a form of tumor, traces its origins to the word "neoplasm," meaning a skew from normality, a change in shape, or an abnormal proliferation, thus breaking the existing harmony [3]. Normal cells become tumor

\footnotetext{
* Corresponding Author: Hye-Young, Kim

Assistant Professor, Department of Dental Hygiene, Kangwon National University, 346 Hwangjo-gil, Dogye-eup, Samcheok-si, Gangwon-do, Korea.
} 
cells through the interaction between external factors such as smoking and viral infection and internal factors such as the hormones [4]. In particular, lung, liver, stomach, colon, breast, esophageal, oral, and cervical cancer have been announced as the eight fatal cancers [5].

The increasing incidence of cancer is a very important societal issue and remains a major global health problem. Oral cancer, in particular, now accounts for 4-5\% of all cancer cases [6]. As the destruction of the external facial appearance and functional loss such as loss of mastication and proper pronunciation from oral cancer not only affect the quality of life of an individual but also inflict a permanent damage on him or her, it makes returning to the society from one's social and emotional disabilities difficult, and worsens a person's daily-life situation [7]. The link between alcohol and tobacco used to have important implications only for elderly people, but it was recently reported that younger people who drink and smoke are at a higher risk of developing certain types of oral cancer [8]. As oral cancer occurs in various kinds of tissue - not only in the muscles, bones, blood canal, and nerves but also in the tissues that construct the oral mucous membrane epithelium and the salivary glands - and can be related with odontogency, the kinds of cancer, their clinical and pathologic expressions, and the reactions to treatment are also varied.

Treatments for oral cancer are gradually developing, but this does not help increase the survival rate [8]. It has been suggested that smoking and drinking are significant factors that can cause oral cancer, along with diet, nutritional deficiency, oral hygiene condition, occupational factors, and viral infection [9]. Blot et al. [10] reported that three-fourths of the oral cancer cases involving Americans are caused by smoking and drinking, and according to another report, compared to non-smokers, smokers have an approximately 10-12 times higher incidence of oral cancer [11]. Additionally, Wynder and Stellman [12] reported that the longer the duration of non-smoking is, the lower the risk of oral cancer. According to Winn et al. [13], the intake of fruits, vegetables, bread, and cereals reduces the risk of developing oral cancer, and the risk of oral cancer is higher in women with a low weight compared to their height. In addition, the incidence of oral cancer has been reported to be higher in the people belonging to the lower social class or whose economic level is so low that they can barely make ends meet, and who are not educated [14].

Few studies on people's knowledge about oral cancer and on the level of their recognition of it have been conducted, however, due to the lack of opportunities for the general people to access information about oral cancer. Thus, this study was conducted to address the need to prevent oral cancer and to lower its mortality rate.

Moreover, as it is important to prevent other oral-cavity-related diseases for oral healthcare, the difference between the incidence of oral diseases and that of oral cancer based on the degree of knowledge about oral health (i.e., the correlation between oral cancer and the degree of knowledge about oral health) was researched in order to prevent such diseases. As such, the correlation between oral cancer and the degree of knowledge about oral health was researched on in this study for the prevention of such disease.

\section{Methods}

A total of 298 adults residing in Kangwon Province were selected for this study. As for the research survey process, the study subjects were provided a self-administered questionnaire, which they were given 2 weeks to accomplish from September 2014. The collected survey data were subjected to statistical analysis using the SPSS ver.18.0 program.

\section{Results}

\subsection{General Characteristics}

According to the subjects' general characteristics, 177 subjects were between the ages of 40 and 59, 113 were male and 185 female, and 131 had a religion and 185 had none. In addition, most of the subjects were married, most (134) were high school graduates, 169 had 
an "intermediate" economic status, 228 were non-smokers, 177 were drinking alcohol, and 183 had no exercise.

\subsection{Recognition of Oral Cancer and the Degree of Oral Healthcare}

The subjects' mean recognition of oral cancer was $19.98 \pm 6.59$, with a minimum of 4 and a maximum of 39. The mean oral healthcare was $23.49 \pm 5.87$, with a minimum of 10 and a maximum of 48 (Table 1 ).

Table 1. Recognition of Oral Cancer and the Degree of Oral Healthcare $(\mathrm{N}=298)$

\begin{tabular}{lllll}
\hline Variables & Mean & SD & Min. & Max. \\
\hline Recognition of oral cancer & 19.98 & 6.59 & 4 & 39 \\
Oral healthcare & 23.49 & 5.87 & 10 & 48 \\
\hline
\end{tabular}

\subsection{Recognition of Oral Cancer and the Degree of Oral Healthcare by General Characteristic}

The recognition of oral cancer was statistically significantly higher at a lower age $(\mathrm{F}=2.76$, $\mathrm{p}=.042)$ and with a higher level of education $(\mathrm{F}=2.62, \mathrm{p}=.035)$ (Table 2). As for oral healthcare, it was significantly higher in the females $(\mathrm{t}=-3.77, \mathrm{p}=.000)$, in the group with higher education $(\mathrm{F}=5.00, \mathrm{p}=.001)$, in the non-smokers $(\mathrm{F}=-4.23, \mathrm{p}=.000)$, and in the group of subjects who were exercising regularly $(\mathrm{t}=4.09, \mathrm{p}=.000)$ (Table 2$)$.

Table 2. Difference between the Recognition of Oral Cancer and Oral Healthcare based on the General Characteristics ( $N=298)$

\begin{tabular}{|c|c|c|c|c|c|}
\hline \multirow{2}{*}{ Variables/categories } & \multirow{2}{*}{ n $(\%)$} & \multicolumn{2}{|c|}{ Recognition of oral cancer } & \multicolumn{2}{|c|}{ Oral healthcare } \\
\hline & & $\mathrm{M} \pm \mathrm{SD}$ & t or $F(p)$ & $\mathrm{M} \pm \mathrm{SD}$ & t or $F(p)$ \\
\hline \multicolumn{6}{|l|}{ Age } \\
\hline Less than 20 & 32 & $22.13 \pm 6.969$ & \multirow{4}{*}{$2.76(.042)$} & $21.53 \pm 6.258$ & \multirow{4}{*}{$1.82(.143)$} \\
\hline $20-39$ & 84 & $20.35 \pm 5.347$ & & $24.10 \pm 5.882$ & \\
\hline $40-59$ & 177 & $19.58 \pm 6.949$ & & $23.62 \pm 5.822$ & \\
\hline Greater than 60 & 5 & $14.20 \pm 6.834$ & & $21.00 \pm 2.449$ & \\
\hline \multicolumn{6}{|l|}{ Gender } \\
\hline Male & 113 & $19.30 \pm 6.747$ & \multirow{2}{*}{$-1.38(.167)$} & $21.88 \pm 5.840$ & \multirow{2}{*}{$-3.77(.000)$} \\
\hline Female & 185 & $20.39 \pm 6.485$ & & $24.47 \pm 5.696$ & \\
\hline \multicolumn{6}{|l|}{ Religion } \\
\hline Yes & 131 & $19.89 \pm 6.710$ & \multirow{2}{*}{$-0.19(.847)$} & $23.69 \pm 6.238$ & \multirow{2}{*}{$0.52(.603)$} \\
\hline No & 167 & $20.04 \pm 6.524$ & & $23.33 \pm 5.594$ & \\
\hline \multicolumn{6}{|l|}{ Marital status } \\
\hline Single & 84 & $21.57 \pm 6.275$ & \multirow{6}{*}{$2.03(.074)$} & $22.51 \pm 5.942$ & \multirow{6}{*}{$1.01(.409)$} \\
\hline Married & 198 & $19.56 \pm 6.683$ & & $23.94 \pm 5.770$ & \\
\hline Divorced & 3 & $17.67 \pm 6.351$ & & $24.33 \pm 9.238$ & \\
\hline Separated & 5 & $15.20 \pm 6.611$ & & $22.20 \pm 8.319$ & \\
\hline Bereaved & 6 & $18.00 \pm 5.692$ & & $24.33 \pm 5.465$ & \\
\hline Others & 2 & $16.00 \pm 0.000$ & & $19.00 \pm 0.000$ & \\
\hline \multicolumn{6}{|l|}{ Educational level } \\
\hline Middle school graduate & 20 & $17.85 \pm 7.741$ & \multirow{2}{*}{$2.62(.035)$} & $18.95 \pm 4.925$ & \multirow{2}{*}{$5.00(.001)$} \\
\hline High school graduate & 134 & $19.28 \pm 6.621$ & & $23.19 \pm 4.909$ & \\
\hline
\end{tabular}




$\begin{array}{llllll}\text { College graduate } & 83 & 20.28 \pm 6.279 & 24.89 \pm 6.357 & \\ \text { Enrolled in a university } & 52 & 21.33 \pm 5.694 & 23.27 \pm 6.937 & \\ \text { Above postgraduate } & 9 & 24.56 \pm 8.777 & 26.22 \pm 4.631 & \\ \text { Family economic level } & & & & & \\ \text { High } & 53 & 19.58 \pm 6.144 & & 21.81 \pm 5.568 & \\ \text { Middle } & 169 & 19.60 \pm 6.592 & 1.46(.223) & 23.49 \pm 5.514 & 3.72(.025) \\ \text { Low } & 76 & 21.09 \pm 6.859 & & 24.66 \pm 6.622 & \\ \text { Smoking } & & & & & \\ \text { Yes } & 70 & 18.83 \pm 6.519 & -1.67(.096) & 20.96 \pm 5.557 & \\ \text { No } & 228 & 20.33 \pm 6.593 & & & -4.23(.000) \\ \text { Drinking alcohol } & & & & & \\ \text { Yes } & 177 & 20.16 \pm 6.439 & 0.57(.566) & 22.99 \pm 5.988 & -1.77(.077) \\ \text { No } & 121 & 19.71 \pm 6.835 & & 24.21 \pm 5.660 & \\ \text { Regular exercise } & & & & & \\ \text { Yes } & 183 & 19.44 \pm 6.406 & 1.78(.075) & 22.41 \pm 5.749 & 4.09(.000) \\ \text { No } & 115 & 20.83 \pm 6.826 & & 25.20 \pm 5.696 & \end{array}$

\subsection{Correlation between the Recognition of Oral Cancer and the Degree of Oral Healthcare}

The recognition of oral cancer and oral healthcare showed a statistically significant static correlation $(\mathrm{r}=.148, \mathrm{p}=.011)$ (Table 3$)$.

Table 3. Correlation between the Recognition of Oral Cancer and Oral Healthcare $(\mathrm{N}=298)$

\begin{tabular}{lll}
\hline Variables & Recognition of oral cancer & Oral healthcare \\
\hline Recognition of oral cancer & 1 & $.148(.011)$ \\
Oral healthcare & $.148(.011)$ & 1 \\
\hline
\end{tabular}

\section{Discussion}

Among the various oral-cavity-related diseases, it is oral cancer whose cause is not yet clear and whose prevention is most important [15]. Its area of exposure is the most obvious among the body regions. Based on the foregoing, the destruction of the external facial appearance and functional loss such as loss of mastication and of proper pronunciation caused by the cancer development can rarely be repaired to normal, making the return to the society from one's social and emotional disabilities quite challenging [7].

Moreover, cancer is the second most common cause of mortality in South Korea, following circulatory diseases. Specifically, the mortality of oral cancer is 1.7 per 0.1 million in males and 0.7 per 0.1 million in females [16]. Oral cancer most commonly occurs in middle-aged and older individuals, although a disturbing number of these malignancies were documented in younger adults in recent years [9]. Intraoral and oropharyngeal tumors are more common among men than among women, with a male:female ratio of over $2: 1$ [17]. The disparity in the male:female ratio, however, became less pronounced in the past half century probably because women have of late been exposing themselves to known oral carcinogens such as tobacco and alcohol as much as the men have [18]. Smoking and drinking have been selected as behavioral factors causing oral cancer [19, 20], and Graham et al. [21] and Maier et al. [22] have postulated that bad oral hygiene and bad dental conditions also increase the risk of oral cancer [23]. Jonson has reported that oral cancer is a self-inflicted disease, therefore 
emphasizing the significance of individual behavior [24], which is considered a causative factor of oral cancer.

As the emphasis of modern medicine is currently showing a shift from treatment to prevention, public health activities focused on oral cavities are actively being carried out [25]. Accordingly, the people's recognition of the importance of good oral health has improved, and individuals are generally exerting greater efforts to maintain their oral health [26]. Thus, the importance of the prevention of oral-cavity-related diseases or of their early detection through regular check-up, and of treating oral-cavity-related diseases and addressing a bad oral condition, which is considered a causative factor of oral cancer, has been reported.

With the improvement of people's recognition of the importance of good oral health, education on oral hygiene is being provided. Here, oral hygiene education aims to change the people's attitude or behavior towards oral health so as to enable them to commit to self-oralhealthcare and to get them interested in it or knowledgeable about it [27]. Although the people's recognition of the importance of good oral health has improved with the development of the media, the country's economic growth, and the development of the medical industry compared to the past, however, it remains insignificant [28].

With regard to the general characteristics, the 40- to 59-year-old age group was the largest age group, with 177 subjects. Of these, 113 were male and 185 female, 131 had a religion and 185 did not, most were married, and 134 were high school graduates (the majority). Also, 169 subjects indicated "middle" as their family economic level, 228 subjects indicated that they were non-smokers, 177 subjects responded "Yes" to whether they were drinking alcohol, and 183 subjects responded "No" to whether they had regular exercise. In the study conducted by Jung et al. [29], more non-smokers in the younger age group (less than 29 years old) than in the older age groups recognized that smoking affects the oral health status, and the recognition of oral cancer itself also appeared to be higher $(58.8 \%)$ in the subjects aged less than 29 years. The reasons for this were reported to be the following: the subjects aged less than 29 years were relatively younger than the other adults and had a higher education level, and their awareness of the disease was greater than that of the other adults. These results seem to be due to the fact that the subjects belonged to the media generation and rapidly accepted and absorbed various information on cancer from many information media, including the Internet and TV.

The mean recognition of oral cancer was $19.98 \pm 6.59$, and the mean oral healthcare was 23.49 \pm 5.87 . The recognition of oral cancer was statistically significantly higher with a younger age $(\mathrm{F}=2.76, \mathrm{p}=.042)$ and was significantly higher with a higher level of education $(\mathrm{F}=2.62, \mathrm{p}=.035)$ (Table 2). With regard to the subjects' recognition of oral cancer, the higher the level of education was, the better the subject's oral health status. Those armed with a college education obtained the highest score (3.02), followed by those with a high school education, and finally, those with a middle school education [30]. Oral healthcare was significantly higher in the female subjects $(\mathrm{t}=-3.77, \mathrm{p}=.000)$, in the group with a high level of education $(\mathrm{F}=5.00, \mathrm{p}=.001)$, in the non-smokers $(\mathrm{F}=-4.23, \mathrm{p}=.000)$, and in the group of subjects who were exercising regularly $(\mathrm{t}=4.09, \mathrm{p}=.000)$. This means that the higher-income group recognized that the majority of people could survive when cancer is detected early through regular check-up, and the lower-income group or those in the lower economic level feel greater anxiety about developing cancer. Therefore, it is important to relieve such anxiety by conveying accurate knowledge about oral cancer at the national level. Researchers observed that leukoplakia of the oral cavity, a precancerous lesion, usually occurs in smokers, and regard the habit of smoking as a cause of leukoplakia of the oral cavity [31]. It has been reported that drinking and smoking are the most likely causes of oral cancer, and that drinking and smoking at the same time is more dangerous than drinking only or smoking only [32].

Based on the study results, the recognition of oral cancer was lower at a younger age, showing a need to provide education on oral cancer. Oral healthcare was well managed in the female subjects, and a good health status was shown in the subjects with a higher level of 
education. The non-smokers and the subjects who were exercising regularly showed wellmanaged oral health.

Based on the subjects' demographic characteristics, it can be concluded that information on the recognition of oral cancer should be gathered continuously, and information on the oral cancer trend should be reported to the public. Early detection and diagnosis through education on oral cancer and oral health, improvement of the patient's habits (e.g., cessation or reduction of smoking), going for regular check-ups, and obtaining education on dental hygiene and prevention policies are necessary.

\section{References}

[1] K. W. Kim and C. H. Nam, “A Study of Students' Knowledge Level of Dental Health Care”, The journal of the korean society of school health, vol. 13, no. 2, (2000), pp.295-317.

[2] B. A. Burt and S. Pai, "Sugar consumption and caries risk: a systematic review", Journal of Dental Education, vol. 65 , no. 10, (2001), pp.1017-1023.

[3] V. Kumar, R. S. Cotran and S. L. Robbins, "Robbins basic pathology 7th", Saunders, Philadelphia, (2003), pp.165-177.

[4] M. Richard, R. Kunnambath, S. Risto, T. Somanathan, T. Gigi and V. R. S. Jissa, "Role of tobacco smoking, chewing and alcohol drinking in the risk of oral cancer in Trivandrum, India: A nested case control design using incident cancer cases", Oral Oncol, vol. 44, no. 5, (2008), pp.446-454.

[5] C. H. Shiboski, S. C. Shiboski and S. J. Silverman, "Trends in oral cancer rates in the United States 19731996", Community Dent Oral Epidemiol, vol. 28, no. 4, (2000), pp.249-256.

[6] S. Subramanian, R. Sankaranarayanan, B. Bapat, T. Somanathan, G. Thomas, B. Mathew, J. Vinoda and K. Ramadas, "Cost-effectiveness of oral cancer screening: results from a cluster randomized controlled trial in India", World Health Organ (2009), vol. 87, no. 3, (2000), pp.200-206.I

[7] H. Maier, J. Zoller, A. Herrmann, M. Kreiss and W. Heller, "Dental status and oral hygiene in patients with head and neck camcer otolaryngology", Head and Neck Surgery, vol. 108, no. 6, (1993), pp.655-661.

[8] C. D. Liewellyn, K. Linklater, J. Bell, N. W. Johnson and S. Warnakulasuriya, "An analysis of risk factors for oral cancer in young people : a case control study", Oral Oncol, vol. 40, no. 3, (2004), pp.304-313.

[9] C. D. Liewellyn, N. W. Johnson and Warnakulasuriya, "Risk factors for squamous cell carcinoma of the oral cavity in young people a comprehensive literature review", Oral Oncol, vol.37, no. 5, (2001), pp.401-418.

[10] W. Blot, J. K. Mclaughlin, D. M. Winn, "Smoking and drinking in relation to oral and pharyngeal cancer", Cancer Res, vol.48, (1998), pp.3282-3287.

[11] P. C. dGupta, J. J. Pindborg and F. Mehta, "Comparison of carcinogenecity of betel quid with and without tobaccol: an epidemiological review”, Ecol Dis, vol. 1, no. 4, (1982), pp.213-219.

[12] E .L. Wynder and S. D. Stellman, "Comparative Epidemiology of Tobacco related Cancers", Cancer Research, vol. 37, no. 4, (1977), pp.4608-4622.

[13] D. M. Winn, R. G. Ziegler, L. W. Pickle, G. Gridley, W. J. Blot and R. N. Hoover, "Diet in the etiology of oral and pharyngeal cancer among women from the Southern United States", Cancer Res, vol. 44, no. 3, (1984), pp.1216-1222.

[14] C. Oji and F. N. Chukwuneke, "Oral cancer in Enugu, Nigeria, 1998-2003”, Br J Oral Maxillofac Surg, vol. 45, no. 4, (2007), pp. 298-301.

[15] L. Lam, R.M. Logan, C. Luke and G. L. Rees, "Retrospective study of survival and treatment pattern in a cohort of patients with oral and oropharyngealtingue cancers from 1987 to 2004", Oral Oncol vol. 43, no. 2, (2007), pp.150-158.

[16] C. Kim, "Comparative study of the prognosis of preperative and postoperative radiation therapy for advanced oral cancer in mandible", Dankook University Graduate School: Dentistry Journal of Oral and Maxillofacial Surgery, (2005).

[17] P. A. Swango, "Cancers of the oral cavity andpharynx in the United States: An epidemiologicoverview", J Public Health Dent, vol. 56, no. 6, (1996), pp. 309-318.

[18] J. K. Chen, R. V. Katz and D. J. Krutchkoff, "Intraoralsquamous cell carcinoma. Epidemiologic patternsin Connecticut from 1935 to 1985", Cancer, vol. 66, no. 6, (1990), pp.1288-1296.

[19] T. Takezaki, K. Hirose, M. Inoue, N.Hamajima, T.Kuroishi, S.Nakamura, T.iKoshikawa, H. Matsuura and K. Tajima, "Tobacco, Alcohol and Dietary Factors Associated with the Risk of Oral Cancer among Japanese", Jpn. J. Cancer Res, vol. 87, no. 6, (1991), pp.555-662

[20] N. Johnson, W. Swarnakulasuriy, and M. Tavassoli, "Hereditary and Environmental Risk Factors; Clinical and Laboratory Risk Markers for Head and Neck, especially oral, cancer and precancer", European Journal of Cancer Prevention, vol. 5, no. 1, (1996), pp. 5-17

[21] S. Graham, H. Dayal, and J. Rohrer, "Dentition, diet, tobacco and alcohol in the epidemiology of oral cancer”, J. Natl. Cancer Inst, vol. 59, no. 6, (1997), pp.1611-1618.

[22] E .L. Wynder and S. D. Stellman, "Comparative Epidemiology of Tobacco related Cancers", Cancer Research, vol. 37, no. 4, (1997), pp.4608-4622. 
[23] N. Gaetano ,M. Sandro, D. Stasio and I. F. Angelillo, "Knowledge and behaviors of primary care physicians on oral cancer in italy", Oral Oncol, vol. 40, no. 5, (2004), pp.490-495.

[24] N. W.Johnson, "Orofacial neoplasms: global epidemiology, risk factors and recommendations for research", Int Dent J, vol. 41, no. 6, (1991), pp. 365-75.

[25] L. J. Pia, C. A. Fabio and M. M. Francisco, "Knowlwdge and attitudes about oral cancer among dentists in Spain", J of Clinical Practice, vol.16, no. 1, (2010), pp.129-133.

[26] S. H. Kim, "A Study on the Oral Hygienic Knowledge of K-College Students in Kyounggi-do", Korea Academic Journal, vol.4, (2000), pp.393-408.

[27] K. S. Ann, "A Study of Comparative Research on the Degree of Recognition and the Actual Condition of Management of Oral Health", Korea Academic Journal, vol. 2, (1998), pp.277-288 .

[28] D. M. Winn, R. G. Ziegler, L. W. Pickle, G. Gridley, W. J. Blot and R. N. Hoover, "Diet in the etiology of oral and pharyngeal cancer among women from the Southern United States", Cancer Res, vol. 44, no. 3, (1984), pp. 1216-1222.

[29] H. Y. Jung M. A. Jung, S. H. Jung, "A Study on the knowledge and Attitude of Adults on Oral Cancer in Sokcho", Korea Public Health researcher, vol. 31, no. 2, (2006), pp.153-169.

[30] G. J. Lee, "Factors Affecting Activities for Oral Health Promotion", Graduate School Daegu Haany University: Department of Health and Welfare for the Elderly, (2011).

[31] J. H. Kwak, "Impacts of Tabacco on Oral Health", Graduate School Seoul National University: School of Dentistry, (2012).

[32] M. L. Gillision, "Current topics in the epidemiology of oral cavity and oropharyngeal cancers", Head Neck, vol. 29 , no. 8, (2007), pp.779-92.

\section{Authors}
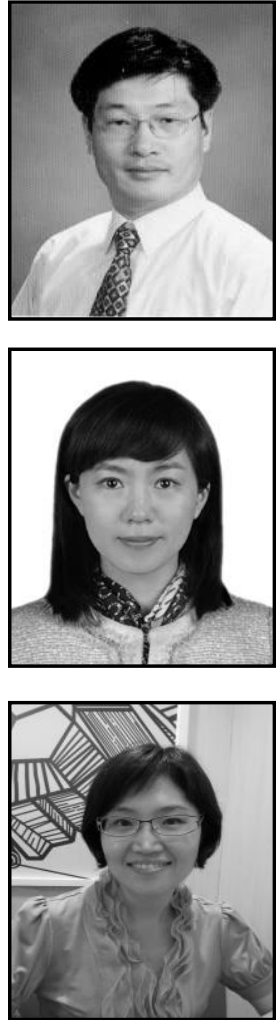

Sung Joong Kim, He is an associate professor in the Department of Physical Therapy at Kangwon National University. He received his MSc in rehabilitation therapy in 2001, and his $\mathrm{PhD}$ in Physical Therapy in 2008. His research interests focus on verifying the effects of massage on physical and psychological aspects and cancer patients.

Young Ran Yeun, She is an assistant professor in the Department of nursing at Kangwon National University. She received her MPH in health promotion in 2008, and her $\mathrm{PhD}$ in nursing in 2012. Her research interests focus on identifying psychosocial risk factors for mental problems and promoting mental health.

Young Hye Kim, She is an assistant professor in the department of dental hygiene at Kangwon National University. She received in MDS in preventive dentistry in 2002, and $\mathrm{PhD}$ in preventive dentistry in 2006. She is interested in preventive dentistry and oral biology research field. 
International Journal of Bio-Science and Bio-Technology

Vol.8, No.4 (2016) 